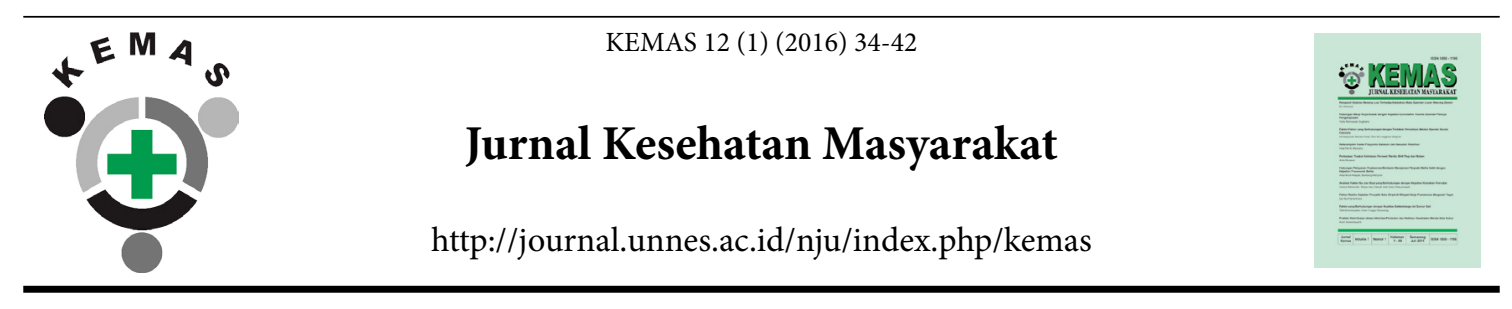

\title{
EFFECT OF AQUAROBIC AND WEIGHT TRAINING ON CORTISOL LEVELS IN OBESE WOMEN
}

\author{
Siti Baitul Mukarromah ${ }^{\circledR}$, Hardhono Susanto $^{2}$, Tandiyo Rahayu ${ }^{1}$ \\ Sport Science Department, Faculty of Sport Science, State University of Semarang \\ Faculty of Mediciness, Diponegoro University
}

\section{Article Info \\ Article History: \\ Submited January 2016 \\ Accepted June 2016 \\ Published July 2016 \\ Keywords: \\ BMI; cortisol; exercise \\ DOI \\ http://dx.doi.org/10.15294/ \\ kemas.v12i1.5510}

\begin{abstract}
Exercise is physical stress which potentially causes disruption of homeostasis, especially in sports that is excessively done. Weight Training (LB) and Aquarobic Exercise (LA) can be modulators of handling stress. This research aimed at investigating the effect of the difference between LB and LA to physical stress in obese women. The study was conducted in 2014. The method used randomized experimental pretest-posttest control group design in 36 obese women, aged 45-50 years who were divided into 3 groups, group LB $50 \%$ RM, 3 sets, 12 repetition, treatment two times a day for 8 weeks $(n=12)$, LA 75\% HRmax, treatment 2 days for 8 weeks $(n=12)$ and control group $(n=12)$. Body Mass Index (BMI) and cortisol levels were measured before and after the treatment. Hypothesis testing was conducted using test (One-Way ANOVA and Kruskal-Wallis) and the mean difference test (Tukey HSD and Mann Whitney's). The results of BMI is increased in the WT group and is decreased in LA group as compared to control group $(\mathrm{p}<0.05)$. The decrease of cortisol level is higher than in LA and LB group and controls $(\mathrm{p}<0.05)$. LB and LA affect the physical stress that is characterized by the increase in cortisol levels in obese women. Conclusion: LB is more dominant than LA in increasing physical stress.
\end{abstract}

\section{Introduction}

Each hormone has a specific function in controlling metabolic; hormonal function is not only influenced by its level but also influenced by many factors, among others: the conditions of the hormone receptors, other hormones, and other metabolic regulators. Sport is one of the physiological stimuli which involves all systems of the body, including muscular system, nervous system and metabolism of the hormone system (Mosavat et al, 2013) and also serves as a very efficient method in controlling stress (Han et al, 2011). Sport can play a role to control neurohormonal, autonomic nervous and behavioral responses of physical and psychological stress. Well-conducted sport has a very important role in improving the health both physically and psychologically, physical fitness, mood and reduce anxiety and prevent depression. Sports with a heavy dose of risk lead to dehydration,

weight loss, chronic stomach problems, hypo or hyperthermia, muscle damage and collapse.

Exercise causes an increase in cortisol both in sport with maximum and submaximal doses (Sugiharto, 2012). Sports involve skeletal muscles at the beginning of the exercise which is influenced by the central command of the motor to the spinal cord through the pyramid by activating simpatoadrenal system. Collateral motor center of the command path activates the central autonomic nervous system in the hypothalamus. Hypothalamus hifofisis adrenal axis (HPA) plays a role in the mechanism of the onset of metabolic response. The hypothalamus $\alpha$-and $\beta$-adrenoreseptor play a significant role in controlling the increase of blood concentrations of epinephrine and norepinephrine. Stress in the body is responded by activating the system cardiorespiratory system locus ceruleus (LC / norepinephrine (NE), the metabolic system and

\footnotetext{
$\square$ Correspondece Address:

Department of Sport Science, State University of Semarang

Email : sitibaitul@mail.unnes.ac.id
} 
the HPA axis (Crowley, 2008). The activity in hypothalamus puitutary adrenal axis (HPA) raises conditioning stimuli in the groove limbic hypothalamus puitutary Adrenal Axis (LHPA axis), then stimulates the hypothalamus and causes the discretion of hormone corticotrophin releasing hormone $(\mathrm{CRH})$, stimulating the hypothalamus to the secretion of ACTH. The increase of secretion of ACTH causes the secretion of cortisol to rise. Hormones are released to maintain homeostasis in the face of stress physically and psychologically. Increased cortisol in some extent is used as an attempt to cope with new demands with the increase in energy demand caused by stressors sports (Astracane, 2007), while both stressors affect the increasing system of cardiorespiratory and neuro-hormonal, as a reflection of the response of the nervous system of autonomy (Autonomic nervous system / ANS), one of which is the sympathetic nervous system (sympathetic nervous system / SNS) (Vink et al, 2013).

Cortisol is a hormone secreted by the adrenal glands due to stress or other chemical signals. While training, the body is not in a state of homeostasis. Therefore, it is perceived as stress inducing for the hormone cortisol in the body. Exercise is a situation where a stressful situation that has been shown to cause inflammatory condition changes with the alteration in immune cells resembling the time of the damage to muscles and immune acute phase. The condition causes increased secretion of cortisol in the body by the adrenal glands. Cortisol response to exercise depends on the duration and intensity of exercise. In general, exercises performed with such moderate intensity aerobic activity will not create changes in cortisol levels in the body (Berg.K.Kupzyk, 2009). Besides being influenced by the intensity and duration of exercise, cortisol responses are also influenced by the fitness status, nutritional status, and the body's circadian rhythms (Beaven et al, 2008). Based on this research, it is found that an increase in cortisol secretion is influenced by the intensity of the exercise with the lipolysis, proteolysis and cytogenesis. The increase of cortisol occurs after a workout with a long duration such as marathons or intensive resistance training. Cortisol levels also increase approximately 2 hours after exercise with the assumption that cortisol role in regulating tissue recovery and repair of damaged tissue (Abd El-Kader, 2011; Westerlind et al, 2012). The effect of weight training and aquarobic exercise toward the cortisol levels are still unclear, it is partly influenced by the intensity and load of the exercise. Lately, it is reported that weight training is done repeatedly can increase cortisol levels in the blood is higher than the maximum isotonic exercises (Beaven et al, 2008).

\section{Method}

This study was an experimental study with randomized pre-test post-test control group design (Kraemer et al, 2007). The study employed this design with the intention to: 1 ) see the expected changes in the experiment group and the control group, 2) firmly investigate the effects of changes before (pre-test) and after treatment (post-test) in the experiment group or the control group, 3) minimize external factors that are not controlled and can interfere observations (Dahlan MS, 2006). The experiment groups were divided into 2 groups: the treatment group P1 with weight training (LB), the treatment group P2 with aquarobics practice (LA) and the control group (K) was not given any training. The study population was obese and healthy women between $45-50$ years old in Central Java with a BMI $>30 \mathrm{~kg} / \mathrm{m} 2$ (Lúcio et al. 2013). The inclusion criteria included female, 45-50 years old, did not have a history of threatening diseases (heart disease, hepatitis, surgery, chronic asthma, etc.), psychologically healthy and willing to sign informed consent. The exclusion criteria specified were taking medications immunostimulant or immunodepresant, had total cholesterol levels> $200 \mathrm{mg} / \mathrm{dL}, \mathrm{LDL}$ cholesterol> 150mg / dL and triglyceride levels $>200 \mathrm{mg} / \mathrm{dL}$ and blood sugar levels (sugar fasting $>110(\mathrm{mg} / \mathrm{dL})$. "Drop out" was taken when the subject did not follow the practice more than twice or when the subjects were sick proven by a medical certificate and the subject was died.

Materials and instruments for data collection in this study were height scale "SMIC ZT 120" with the accuracy scale of $0.1 \mathrm{~cm}$, weight scale "SMIC ZT 120" with accuracy scale $0,01 \mathrm{~kg}$, heart rate recording devices polygreen KP-6230 and omron HR-100C, stopwatch 
timer tool "Citizen" with accuracy scale of 0.01 seconds, skinfold calipers with accuracy scale of $0.1 \mathrm{~mm}$, EDTA tube, a set of Immunoassay, ELISA suite of tools, the blood-making tool, a set of weight training and compact disc.

For data collection techniques, the collected data was primary data obtained from measurements of biochemical and anthropometric examination. Blood samples were taken from the vein blood vessels which were then inserted into EDTA tube. The blood samples were examined by immunoassay to calculate cortisol levels using ECLIA/ ELISA method. The calculation of the heart rate was conducted by recording the time of heartbeat achievement at the beginning of exercise to complete the exercise and postexercise (recovery). The monitoring of heart rate before exercise was done from the start to the finishing of practice through observing each practice session during the 8 weeks of treatment. Data collection technique was conducted by recording the subjects' heart rate before the exercise in a sitting position, then the subject did 5-10 minute warming up. The heartbeat was recorded again every 5 minutes until it returned to the initial heart rate before exercise in a sitting position. By the time of the study, subjects were divided into 3 groups, group LB with intensity of $75 \%$ RM frequency of once in two days, 12 repetition, 3 sets for each movement for 8 weeks. Second group was the group LA with intensity of $75 \%$ HRmaks frequency of once in two days for 8 weeks. And the third was a control group without treatment. LB on the study includes upperbody and lowerbody movement. Upperbody movement consisted of six movements of the bench press (barbell), seated rows, biceps curl dumbbells, doumbbell shoulder press, lat pulldown and triceps pushdown. Lowerbody movement consisted of six movements of leg press, leg curl (hamstrings), leg extension (quadriceps), calf raises, abdominal crunch and lower leg raises (Scott et al, 2011). The intensity of exercise in this study was $75 \%$ RM, 3 sets / 12 repetitions a frequency of once in two days for 8 weeks. LA Program included movements of aquarun, aquajogging and Aquafun (William et al, 2010).

For data analysis, the data were samples' height, weight, BMI, and cortisol levels. The data had been processed, edited, tabulated and analyzed with the following stages: data that was presented in nominal and ordinal frequency distribution, data that was presented in the interval and the ratio of mean and standard deviation was then presented in the form of graphs and tables. The test of hypothesis was conducted through normality test data with the Shapiro-Wilk test and homogeneity test was conducted through a homogeneity test of variance Levene statistics against data. Normal distribution of data $(p>0.05)$ and variants of homogeneous data were analyzed by parametric one-way ANOVA followed by Tukey HSD post hoc test (significantly different). Distributed data was not normal $(\mathrm{p}<0.05)$ or a variant not homogeneous done by non-parametric analysis using the Kruskal-Wallis test and Mann continued test-Whitney. The multivariate analysis was conducted to determine the effect of multiple factors to simultaneously decrease obesity and increase bone remodeling, and to determine the most dominant factors of all the variables (Dahlan MS, 2006). Ethical clearance was obtained from the Research Ethics Committee of Health and Medicine, Faculty of Medicine, University of Diponegoro 298 / EC / FK / RSDK / 2012.

\section{Results and Discussion}

The summary of research activities was stated in the Consolidated Report of Trial (Consort) presented in Figure 1. Sixty people attended socialization and guidance prior to the study to obtain informed consent, 42 people expressed willingness to participate in research. Screening process was conducted through a process of inclusion and exclusion including by examining electrocardiographic (ECG), lipid profile, photos rongten pelvis, percent body fat, and BMI. Thirty six eligible subjects were randomly selected which were qualified for inclusion and exclusion standards. The subjects were then divided into 3 groups: group 1 (P1) LB, group 2 (P2) LA and a control group without treatment, each group consisted of 12 people. Treatment was given for 8 weeks. Before the treatment, preliminary tests (pre-test) was conducted and after 8 weeks of treatment, a final test (post-test) was also carried out.

The mean of age on subjects, the intake 


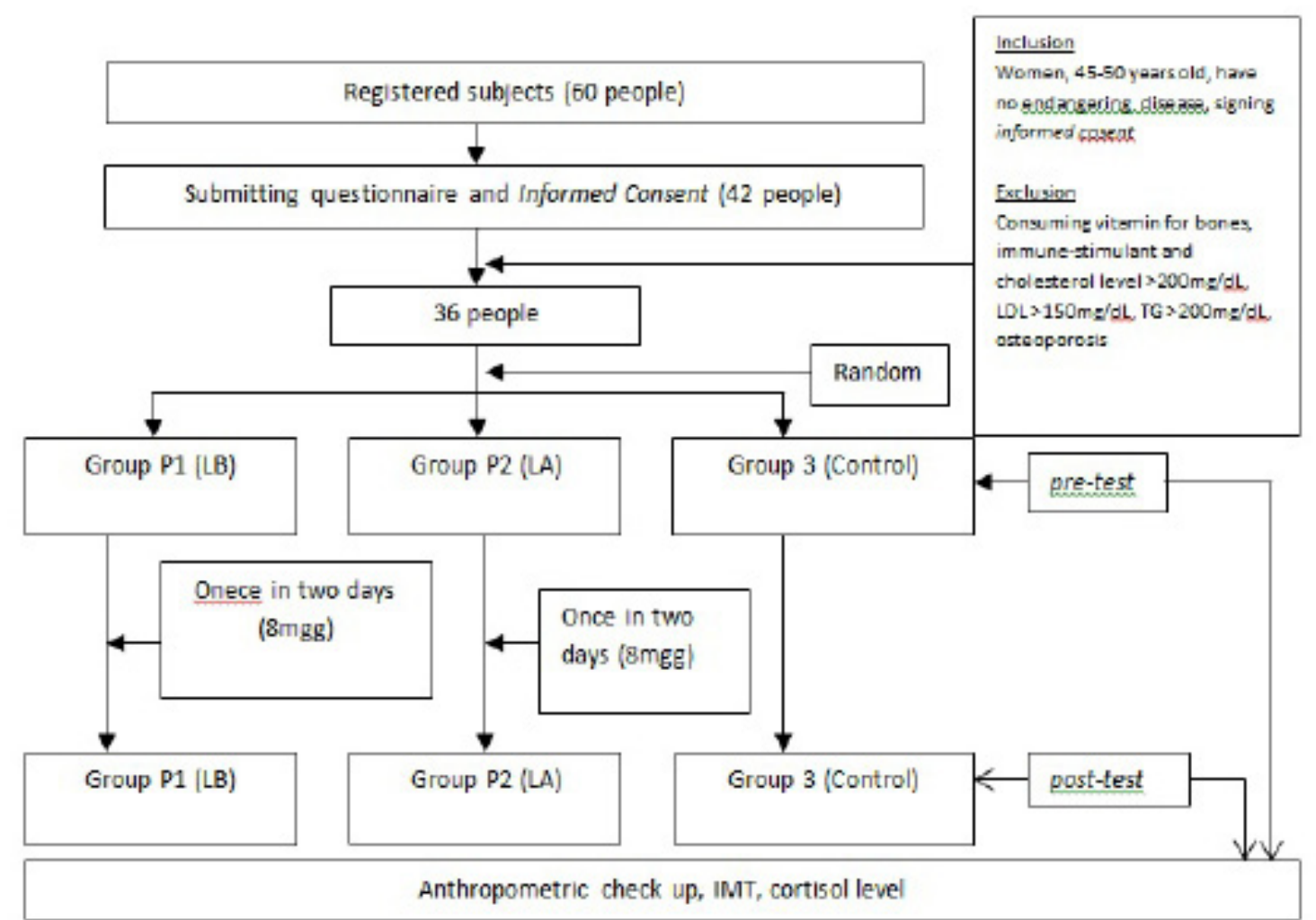

Figure 1. Diagram Consort (Consolidated Report of Trial)

of energy, protein, fat intake, height, weight and body fat percentage before treatment in all groups were not statistically significant. The recommendation for dietary allowance for Indonesia based on the level of age and sex is that the energy requirement for women aged $30-49$ years is $2.625 \mathrm{kkal}$, $65 \mathrm{~g}$ protein, $73 \mathrm{~g}$ fat and energy requirements for women aged $50-64$ is $2.325 \mathrm{kkal}, 65 \mathrm{~g}$ protein and $65 \mathrm{~g}$ fat. In this study, measurement of food intake using a 24-hour food recall was based on the calculation software nutrisoft note that the level of consumption of energy, protein and fat in their respective groups was not significant ( $p>$ 0.05 ). The results show that in all groups of food intake during the treatment is the same (Table. $1)$.

The BMI of the LB group $(31.72 \pm 1.13)$, LA (31.29 \pm 0.98$)$ and control group (32.47 \pm 1.55 ), IMT different test subjects before treatment show no significant difference ( $>$ > 0.05). The mean of BMI after 8 weeks of treatment in the LB group (32.86 \pm 0.93$)$, LA $(30.29 \pm 1.15)$ and control group $(32.46 \pm 1.54)$, IMT different test after treatment and delta BMI between groups show significant differences ( $\mathrm{p}$ $<0.05$ ) (Fig.2). The mean of cortisol levels before treatment in the LB group $(9.67 \pm 3.37)$, LA $(9.55 \pm 2.17)$ and control group $(7.70 \pm 1.65)$, and different test subjects cortisol levels before treatment shows no significant difference ( $\mathrm{p}>$ $0.05)$. The mean cortisol levels after 8 weeks of treatment in the LB group $(8.60 \pm 3.51)$, LA $(5.91 \pm 1.98)$ and control group $(9.79 \pm 1.44)$ different test cortisol levels after treatment show significant difference $(\mathrm{p}<0.05)$. Different test of delta cortisol levels between the treatment groups shows significant difference between treatment groups $(\mathrm{p}<0.05)$ (Figure 3$)$. The mean of cortisol levels are presented in Table. 2

In this study, the changes in BMI at $\mathrm{LB}$ and LA are significantly different $(p=0.000)$. In the group of LB, IMT is increased. In contrary, IMT is declined in the LA group. Increased IMT on LB group is associated with increased body weight (Reid 2008). LB gives a direct influence on muscles, namely the addition of sarcomeres and the number of muscle fibers (filaments of actin and myosin are needed in muscle contraction). The addition of new muscle fibers causes increased muscle strength resulting in weight gain. Other studies have reported that muscle glycogen was increased from the 
Table 1. Characteristics of the Study Subjects

\begin{tabular}{lllll}
\hline Variable & LB $(\mathrm{n}=12)$ & LA $(\mathrm{n}=12)$ & Control $(\mathrm{n}=12)$ & $\mathrm{p}$ \\
& Mean $\pm \mathrm{SB}$ & Mean $\pm \mathrm{SB}$ & Mean $\pm \mathrm{SB}$ & \\
\hline Age & $46,49 \pm 1,41$ & $46,74 \pm 1,30$ & $46,79 \pm 1,35$ & $0,225^{(1)}$ \\
Energy Intake (kkal) & $2157 \pm 119.97$ & $2125 \pm 165.81$ & $2134 \pm 136.11$ & $0,112^{(1)}$ \\
Protein Intake $(\mathrm{g})$ & $48,38 \pm 1,67$ & $44,91 \pm 1,63$ & $45,38 \pm 1,78$ & $0,608^{(1)}$ \\
Fat Intake $(\mathrm{g})$ & $69,87 \pm 3,83$ & $63,93 \pm 3,12$ & $65,66 \pm 3,34$ & $0,265^{(1)}$ \\
height $(\mathrm{m})$ & $1,52 \pm 0,04$ & $1,55 \pm 0,05$ & $1,52 \pm 0,04$ & $0,151^{(1)}$ \\
weight $(\mathrm{kg})$ & $76,41 \pm 3,11$ & $75,66 \pm 5,54$ & $75,41 \pm 6,61$ & $0,539^{(1)}$ \\
\hline
\end{tabular}

Source: Primary Data

(1) one-way anova, ${ }^{(2)}$ Kruskal-Wallis, $\mathrm{LB}=$ weight exercise; LA= Aquarobics exercise, significant $\mathrm{p} \leq 0,05$

normal price of $13-15 \mathrm{~g} / \mathrm{kg}$ of muscle to $40 \mathrm{~g} /$ $\mathrm{kg}$ of muscle or 2.5 times more is needed by the body (Rose \& Richter, 2009).

Reductions in BMI in LA are due to weight loss and body composition changes, large amount of water loss, electrolytes, minerals and proteins that are fat tissue accompanied by the use of liver and muscle glycogen stores. For every gram of glycogen lost, there will be loss of water as much as 2.5 grams. Contraction of skeletal muscle $(40 \%)$ of all body tissues requires energy source intake (Burd et al, 2009). In phyisio-biology, skeletal muscle energy reserves to meet the energy needs during a contraction. One of the fulfillments of these sources is through the mechanism of lipolysis. Lipolysis occurs by exposure to epinephrine through the mechanism of activity of beta adrenergic response is secreted during stress on physical exercise and immediately after exercise (Kim et al, 2009). The increase of lipolysis in physical exercise can reduce fat content in adipocyte that adipocyte cells to shrink, further adipocyte size reduction causes a decrease in fat tissue mass. Energy used for aerobic exercise comes primarily from fat, because fat will produce more energy than carbohydrates or protein (Punyadeera et al, 2005). The results of this study support the previous research that physical exercise $25 \%-60 \% \mathrm{VO}_{2}$ max increases fat oxidation in 5-10 times. Increased lipolysis occurs after 30 minutes in subjects who are not trained, slowly approaching slower lipolysis (Laye et al, 2010; Manning, 2011).

Weight training and aquarobic exercises are a stress which proves that it can cause

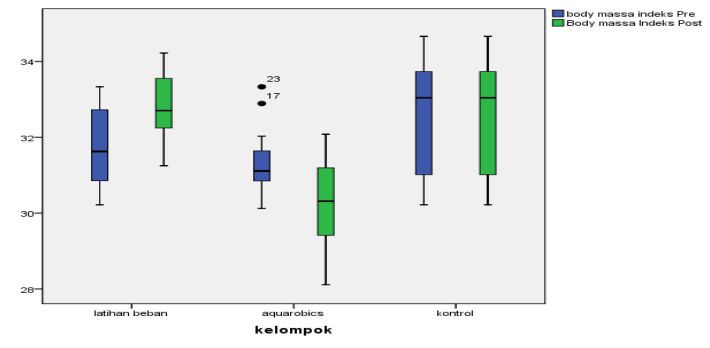

Picture. 2. Box Diagram of IMT Plot in Each Group, Before and After Treatment

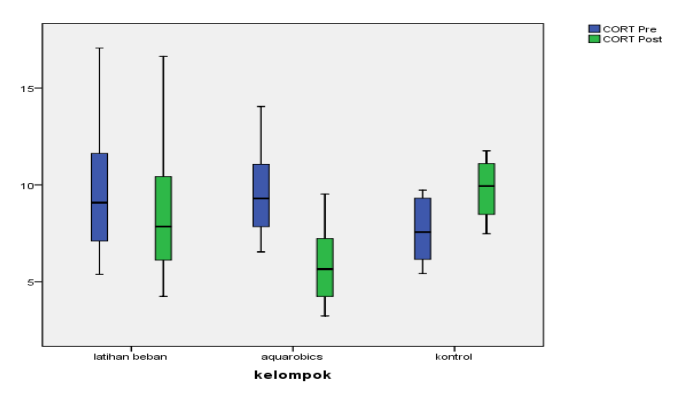

Picture. 3. Box Plot Diagram of Cortisol Levels in Each Group

inflammation in the body; causing changes in the immune cells from infection and muscle damage. The cortisol increase concentrations during exercise done in a long duration due to the accumulation of increased stress. This is related to the function of cortisol as an antiinflammatory and anti-immunosuppressive. Long practice will reduce muscle glycogen reserves, and it will stimulate increased secretion of cortisol because cortisol plays a role in maintaining blood glucose levels. Increased secretion of cortisol is a common response to 


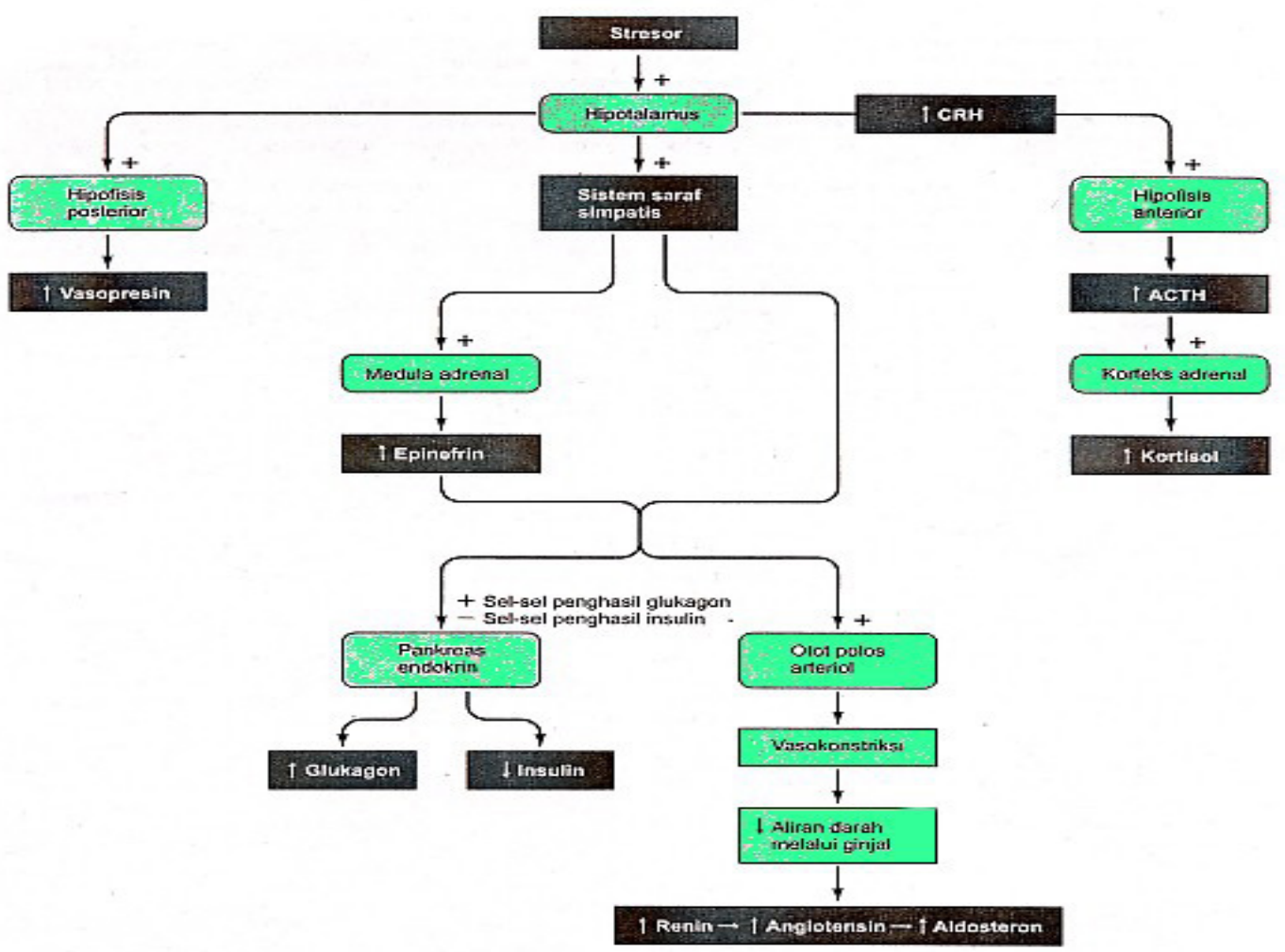

Figure 4. Integration of the Stress Response by the Hypothalamus (Sherwood, 2001)

stress. Therefore, in a light workout in which the stress level low, cortisol levels does not change significantly. On the other hand, during strenuous exercise in which the maximum stress level then cortisol levels will rise. Cortisol at practice will affect gluconeogenic in the liver that can increase the formation of glucose from sources nonkarbohidrat (fat and protein) so as to make glucose as metabolic fuel (gluconeogenesis) (Miyata et al,2011; Ramudu et al, 2008).

The increase of cortisol levels in this study is due to the mechanism of the body who they in response to stress biologically that people are closely related to the interaction of neuroendocrine and immune responses. Management cell, which means the cells can function properly and create smooth communication between cells, allows optimal functioning tissue and organs in order to respond to the stress or environmental changes inside and outside the body. Cell interactions involves the endocrine system such as the axis of the Hypothalamic-Pituitary-Thyroid (HHT), Hypothalamic-Pituitary-Adrenal (HHA), Hypothalamic-Pituitary-Gonade (HHG). Evidence is found that endocrine hormones that have a role setting function of the elements of the immune system such as lymphocytes, macrophages, mast cells, etc. (Mosavat et al, 2013; Tartibian et al, 2010).

Weight training and aquarobik exercise directly affect the HHA axis response (Hypothalamic-Pituitary-Adrenal) which is a biomarker of stress. This activity reflects the interaction of axis that runs on immuneneuroendocrine system in the body. Adrenal hormones are already becoming a popular tool for health practitioners to evaluate pathobiology of fatigue, lethargy, and insomnia. The emergence of adrenal imbalance can be a signal or alarm that the body functions that is declining. Products adrenal gland is known to work affects almost all body functions, from energy production to control inflammation. Hormones, cytokines and molecules are related to signaling molecules to bring change stress response regulation, the intensity of the immune function, energy metabolism, growth, and reproductive functions (Holmes et al, 2010). The pattern of biological response to stress by axis HHA or adrenal glands, in principle, can be divided into pattern of acute and chronic patterns. Acute Stress has pro-inflammatory 
effects, is mediated by mast cells with the ability to set the blood-brain barrier (BBB), and is so vulnerable to inflammation in the brain (Vink et al, 2013). The presence of acute stress causes the activity of the periventricular nucleus $(\mathrm{PVN})$ of the hypothalamus increases. Then stimulate the release of $\mathrm{CRH}$, and this moment is with increased catecholamine activity. CRH stimuli on kortikotrof cells in in hipofise and stromal cells in the adrenal cascade through the flow of the JAK / STAT which can be seen with the active protein Fos / Jun who are switching on cellular activity. These stimuli resultss in POMC and ACTH secretion, both systemic and local action and increase levels of cortisol (Deuster et al, 2005).

The cortisol in physiologic level is required for normal function of lymphocytes. It is given the cortisol receptor which is a cellular transcription factor. In an acute situation, the increase in cortisol levels is very striking, changing the distribution of lymphocytes and suppress the function of both humoral and cellular adaptive as fight and flight response. High levels of cortisol can achieve a 5-10 times. This is a mechanism to cope with stress (coping mechanism), then is followed back to normal ACTH. ACTH and cortisol dissociation is possible because of the "ancillary regulatory mechanism" (Liao et al, 2013; Deuster et al, 2005). The needs of this stress hormone is to prepare the body in a physiological function for mobilization of muscular activity, supplying of glucose as an energy source of the brain and muscles, controlling inflammation and improving heart and lung function in addressing the critical state (Azizi et al. 2012).

Prolonged rise in cortisol can interfere glucose metabolism in the hippocampus region of the brain that will result in their memory deficits. High levels of cortisol which are consumed constantly can cause neuronal injury due to the ability of cortisol to trigger programmed cell death, both apoptotic and non-apoptotic (Haussmann et al, 2007). For elderly, it can be seen through the cognitive deficits and executive dysfunction that the damage which be exacerbated by aging or other damaging factors related to the stress on cells, such as adaptation to autophagy and a reduction of cell function (Sorichter et al, 2012;
Moore et al, 2005).

\section{Conclusion}

The increase level of cortisol is a good indicator for someone who is experiencing chronic stress or repetitive stress because chronic stress suppresses the body's immune system as a result of the effects of cortisol. Cortisol secretion during exercise is influenced by the intensity and duration of exercise, but it is also influenced by the fitness status, nutritional status, and diurnal rhythms. In general, moderate to high intensity exercise with long duration will further increase cortisol levels as compared to low intensity exercise of short duration

\section{Acknowledgement}

My biggest gratitude is addressed to LPPM of State University of Semarang that has funded this research, as well as to all those who have participated in the completion of this study.

\section{References}

Abd El-Kader, S.M., 2011. Aerobic Versus Resistance Exercise Training in Modulation of Insulin Resistance, Adipocytokines and Inflammatory Cytokine Levels in Obese Type 2 Diabetic Patients. Journal of Advanced Research, 2(2),179-183.

Astracane, V.D.A.C., 2007. Exercise and Humoral Mediators of Peripheral Energy Balance: Ghrelin and Adiponectin. 184-194.

Azizi, M., Rahmani-nia, F. \& Mohebbi, H., 2012. Cortisol Responses and Energy Expenditure at Different Times of Day in Obese Vs . Lean Men. , 6(3).314-320.

Beaven, C.M. et al, 2008. Dose Effect of Caffeine on Testosterone and Cortisol Responses to Resistance Exercise. International journal of sport nutrition and exercise metabolism, 18.131-41.

Berg.K.Kupzyk et al, 2009. The Effect of Weight Training on Bone Mineral Density and Bone Turnover in Postmenopausal Breast Cancer Survivors with Bone Loss: a 24-month randomized controlled trial. Osteoporos Int.

Burd, N. a et al, 2009. Exercise training and protein metabolism: influences of contraction, protein intake, and sex-based differences. Journal of applied physiology (Bethesda, Md. : 1985), 106(5).1692-701.

Crowley, V.E.F., 2008. Overview of Human Obesity 
and Central Mechanisms Regulating Energy Homeostasis. Annals of clinical biochemistry, 45(Pt 3). 245-55.

Dahlan MS, 2006. Besar sampel dalam penelitian Kedokteran dan Kesehatan, Jatinangor: Alqa Print.

Deuster, P. 2005. Effects of Dehydroepiandrosterone and Alprazolam on Hypothalamic-Pituitary Responses to Exercise. Journal of Clinical Endocrinology and Metabolism, 90(8).47774783.

Han, G., Cho, B. \& Young, M.T., 2011. Endurance Exercise Reduces Oxidative Stress in Mice. Journal of Physical Therapy Science, 23(4).539-541.

Haussmann, M.F., Vleck, C.M. \& Farrar, E.S., 2007. A Laboratory Exercise to Illustrate Increased Salivary Cortisol in Response to Three Stressful Conditions Using Competitive ELISA. Advances in physiology education, 31.110-115.

Holmes, M.E., Ekkekakis, P. \& Eisenmann, J.C., 2010. The Physical Activity, Stress and Metabolic Syndrome Triangle: A Guide to Unfamiliar Territory for the Obesity Researcher. Obesity Reviews, 11(7) 492-507.

Kim, M.-K. et al, 2009. Aerobic exercise Training Reduces Epicardial Fat in Obese Men. Journal of applied physiology (Bethesda, Md. : 1985), 106(1).5-11.

Kraemer, R.R., Castracane, V.D. \& Astracane, V.D.A.C., 2007. Experimental Biology and Medicine.

Laye, M.J. et al, 2010. Cessation of Daily Wheel Running Differentially Alters Fat Oxidation Capacity in Liver, Muscle, and Adipose Tissue.161-168.

Liao, Y.-H. et al, 2013. Effect of Dehydroepiandrosterone Administration on Recovery from Mix-Type Exercise TrainingInduced Muscle Damage. European journal of applied physiology, 113(1).99-107.

Lúcio, M. et al, 2013. The Effects of 16 Weeks of Exercise on Metabolic Parameters, Blood Pressure, Body Mass Index and Functional Autonomy in Elderly Women $1 \mathrm{Mr}$. International SportMed Journal, 14(2). 86-93.

Manning, K., 2011. Effects of Exercise Training on Fat Oxidation in Untrained Overweight and Obese Females,

Miyata, T., Tanaka, S. \& Yamazaki, T., 2011. Effects of Walking and Weight-bearing Exercise on Soleus Muscle in Hindlimb-Suspended Rat. Journal of Physical Therapy Science, 23(3).385-389.

Moore, A. et al, 2005. Strenuous, Fatiguing Exercise:
Relationship of Cortisol to Circulating Thyroid Hormones. Int J Endocrinol Metab, 1. 18-24.

Mosavat, M., Mohamed, M. \& Mirsanjari, M.O., 2013. Effect of Exercise on Reproductive Hormones in Female Athletes. International Journal of Sport and Exercise Science, 5(1).712.

Punyadeera, C. et al, 2005. The effects of exercise and Adipose Tissue Lipolysis on Plasma Adiponectin Concentration and Adiponectin Receptor Expression in Human Skeletal Muscle. European journal of endocrinology / European Federation of Endocrine Societies, 152(3).427-36.

Ramudu, K. et al, 2008. Effect of Carbohydrate Supplementation on Postexercise GLUT4 Protein Expression in Skeletal Muscle. Chinese Journal of Physiology, 48(1).23-29.

Reid, I.R., 2008. Relationships between Fat and Bone. Osteoporosis international: a journal established as result of cooperation between the European Foundation for Osteoporosis and the National Osteoporosis Foundation of the USA, 19(5).595-606.

Rose, A.J. \& Richter, E. a, 2009. Regulatory Mechanisms of Skeletal Muscle Protein Turnover During Exercise. Journal of applied physiology (Bethesda, Md.: 1985), 106(5).1702-1711.

Scott, J.P.R. et al, 2011. The Role of Exercise Intensity in the Bone Metabolic Response to an Acute Bout of Weight-Bearing Exercise. Journal of applied physiology (Bethesda, Md.: 1985), 110(52).423-432.

Sherwood, 2001. Fisiologi Manusia dari Sel ke Sistem, Jakarta: ECG.

Sorichter, S. et al, 2012. Skeletal Troponin I as a Marker of Exercise-Induced Muscle Damage Skeletal Troponin I as a Marker of ExerciseInduced Muscle Damage.1076-1082.

Sugiharto, 2012. Fisioneurohormonal Pada Stresor Olahraga. Jurnal Sains Psikologi, 2. 54-66.

Tartibian, B., Maleki, B.H. \& Abbasi, A., 2010. The Calciotropic Hormone Response to Omega-3 Supplementation During LongTerm Weight-Bearing Exercise Training in Post Menopausal Women. 245-252.

Vink, N.M. et al, 2013. Basal or Stress-Induced Cortisol and Asthma Development: The trails study. European Respiratory Journal, 41(4). 846-852.

Westerlind, K.C. et al, 2012. Effect of Resistance Exercise Training on Cortical and Cancellous Bone in Mature Male Rats Exercise Mice Mice Effect of Resistance Exercise Training 
Siti Baitul Mukarromah / Effect of Aquarobic and Weight Training on Cortisol Levels in Obese Women

on Cortical and Cancellous Bone in Mature Male Rats. J Appl Physiol. 459-464.

William M. Denning, 2010. The Effects of Aquatic Exercises on Physiological and Biomechanical Respons, Utah State University. 